\title{
The modulation study of multiple drug resistance in bladder cancer by curcumin and resveratrol
}

\author{
CHUN-JUNG CHO ${ }^{1,2^{*}}$, CHING-WEI YANG ${ }^{3 *}$, CHIA-LUN WU ${ }^{2}$, JAR-YI HO ${ }^{1,4}$, \\ CHENG-PING YU ${ }^{1}$, SHENG-TANG WU ${ }^{2}$ and DAH-SHYONG YU ${ }^{2}$
}

\author{
${ }^{1}$ Graduate Institute of Pathology and Parasitology, National Defense Medical Center; ${ }^{2}$ Division of Urology, \\ Department of Surgery, Tri-Service General Hospital, National Defense Medical Center, Taipei 114; \\ ${ }^{3}$ Department of Urology, Cheng-Hsin General Hospital, Taipei $112 ;{ }^{4}$ Graduate Institute of Life Sciences, \\ National Defense Medical Center, Taipei 114, Taiwan, R.O.C.
}

Received November 27, 2018; Accepted July 10, 2019

DOI: $10.3892 / \mathrm{ol} .2019 .11023$

\begin{abstract}
Gemcitabine (GCB), which functions via the inhibition of DNA synthesis, is commonly used in the treatment of bladder cancer; however, its response rate is not satisfactory due to the development of drug resistance. The potential for phytochemicals to reverse drug resistance in bladder cancer tumor cells was evaluated. A human bladder cancer cell line, T24, was cultured, and GCB-resistant cells (T24-GCB) were also established. The acquired resistance of T24-GCB to GCB was measured using an MTT assay. The gene expression of ATP-binding cassette (ABC) transporter protein family members was analyzed using reverse transcription-quantitative PCR analysis, and western blotting was performed to verify $\mathrm{ABC}$ family protein, cytoplasmic thymidine kinase (TK) and poly (ADP-ribose) polymerase (PARP) expression on whole cell lysates. Subsequently, resveratrol and curcumin were used to evaluate their modulation potential in decreasing the drug resistance of T24-GCB cells to GCB using MTT and migration assays. T24-GCB cells have increased drug resistance ability, with an 18.75 -fold higher $\mathrm{ID}_{50}$ value compared with native T24 cells (105 vs. $5.6 \mathrm{nM}$ ). T24-GCB cells also exhibit increased cross resistance to mitomycin $\mathrm{C}$ and paclitaxel. The mRNA expression of ABCC2 in T24-GCB cells increased compared with that in native T24 cells. Via western blot analysis, it was determined that the expression of $\mathrm{ABCC} 2$ protein was also increased in T24-GCB cells. Conversely, the expression of
\end{abstract}

Correspondence to: Professor Dah-Shyong Yu, Division of Urology, Department of Surgery, Tri-Service General Hospital, National Defense Medical Center, 325, Section 2, Chenggong Road, Taipei 114, Taiwan R.O.C.

E-mail: yuds45@gmail.com

*Contributed equally

Key words: bladder cancer, multidrug resistance, gemcitabine, phytochemicals, curcumin, resveratrol, ATP-binding cassette family, poly (ADP-ribose) polymerase, thymidine kinase
ABCB1, ABCG2, deoxycytidine kinase (DCK), TK1 and TK2 decreased. Following curcumin and resveratrol treatment alone or combined with GCB, additive cytotoxic enhancement was observed, and the migratory abilities of T24-GCB cells were significantly decreased. Western blot analysis revealed that $\mathrm{ABCC} 2$ protein expression increased, and DCK, TK1 and TK2 expression decreased following co-treatment of T24-GCB cells with GCB + curcumin or resveratrol compared with GCB alone. Of note, there was a marked increase in cleaved-PARP expression in T24-GCB cells treated with a combination of GCB + curcumin or resveratrol. Both curcumin and resveratrol could reverse the drug resistance of T24-GCB cells in an additive pattern though PARP enhancement without changes in ABCC2 and DCK, TK1 and TK2 expression.

\section{Introduction}

Bladder cancer, the most common transitional cell carcinoma or urothelial cell carcinoma (UCC), is among the top 10 most prevalent cancers worldwide (1). It is a highly recurrent and metastatic malignancy that is refractory to chemotherapy and radiotherapy, which decreases its therapeutic efficacy and prognosis (2). Gemcitabine (GCB) is a deoxycytidine analogue with promising antitumor activity, which has been comprehensively used in several types of combined treatment of UCC (2). However, GCB-resistant UCC has been reported, which has also been associated with multidrug resistance (MDR). MDR refers to a phenomenon where cancer cells have a reduced susceptibility to a chemotherapeutic agent following extensive exposure to it, and subsequently develop cross-resistance to different chemotherapeutic drugs $(1,2)$. MDR mechanisms include decreased uptake of the drug, reductions of intracellular drug concentrations by efflux pumps, altered cell cycle checkpoints, increased metabolism of the drug and impaired apoptotic pathway (3).

ATP-binding cassette (ABC) transporters represent a highly conserved family of transmembrane proteins comprised of 49 members classified into seven gene super families $(A B C A-G)(4)$. ABC transporters fundamentally participate in the substrate influx and efflux of cells upon ATP hydrolysis; their enhanced expression has been reported 
in several types of cancer, including breast cancer and renal cancer, and has been associated with the efflux of a wide variety of cytotoxic drugs, therefore becoming the most reported field of chemoresistance (4). At present, several $\mathrm{ABC}$ transporters have been reported as potent drug pumps involved in MDR, including ABC superfamily B member 1 (ABCB1; also known as multidrug resistance protein 1 and P-glycoprotein), ABC superfamily G member 2 (ABCG2; also known as breast cancer resistance protein) and $\mathrm{ABCC} 1$ (also known as multidrug resistance-associated protein 1); these pumps were reported to be dysregulated and responsible for MDR in several types of cancer, including breast cancer, colon cancer and prostate cancer (5-8). Therefore, the present study was designed to determine the underlying mechanisms of GCB resistance and identify novel potential therapeutic strategies for GCB resistance in bladder cancer. In addition to investigating the dysregulation of GCB metabolic pathway, the association between $\mathrm{ABC}$ transporter dysregulation and $\mathrm{GCB}$ resistance was also investigated.

Phytochemicals, chemicals found naturally in plants, regulate and protect the health of humans through their antioxidant and anti-inflammatory effects (9), although they are not essential nutrients. In addition, several phytochemicals have been reported to affect cancer cell survival. Curcumin, silymarin and resveratrol phytochemicals may prevent tumorigenesis by inhibiting or retarding tumor progression, or by promoting cell differentiation in cancer (9-11). Thus, phytochemicals may provide insight into discovering novel therapeutic compounds to treat GCB-resistant UCC cells. The aim of the present study was to explore whether curcumin and resveratrol could modulate the GCB resistance of bladder cancer and identify the mechanisms involved.

\section{Materials and methods}

Reagents. Avastin was used at $25 \mathrm{mg} / \mathrm{ml}$, was stored at $2-8^{\circ} \mathrm{C}$ and obtained from Roche Diagnostics. Doxorubicin was used at $2 \mathrm{mg} / \mathrm{ml}$, was stored at $2-8^{\circ} \mathrm{C}$ and obtained from (TTY Biopharm Company Ltd.). Epirubicin was used at $2 \mathrm{mg} / \mathrm{ml}$, was stored at $2-8^{\circ} \mathrm{C}$ was purchased from Pfizer, Inc. Mitomycin $\mathrm{C}$ was used at $0.4 \mathrm{mg} / \mathrm{ml}$ was stored at $<25^{\circ} \mathrm{C}$ and purchased from Kyowa Hakko Kirin Co., Ltd. and paclitaxel was used at $6 \mathrm{mg} / \mathrm{ml}$, was stored at $15-30^{\circ} \mathrm{C}$ and purchased from Yung Shin Pharmaceutical Industrial Co., Ltd.

Cell lines. T24 (ATCC ${ }^{\circledR}$ HTB- ${ }^{\mathrm{TM}}$ ), a bladder carcinoma cell line, was cultured in RPMI-1640 medium supplemented with $10 \%$ FBS (both from Corning, Inc.) and $100 \mathrm{U} / \mathrm{ml}$ penicillin at $37^{\circ} \mathrm{C}$ in a humidified atmosphere with $5 \% \mathrm{CO}_{2}$. GCB-resistant T24, (T24-GCB), was cultured in RPMI-1640 medium with $10 \% \mathrm{FBS}, 100 \mathrm{U} / \mathrm{ml}$ penicillin and $0.5 \mathrm{nM}$ GCB (TTY Biopharm, Co, Ltd.) for a minimum of 8 weeks.

MTT assay of GCB cytotoxicity to T24 and T24-GCB cells. Cellular chemo-sensitivity was evaluated using a modified MTT assay to determine cell viability in vitro. In brief, T24 and T24-GCB (1,500 cells/well) in $100 \mu \mathrm{l}$ RPMI culture medium were seeded into 96 -well microplates and incubated for $16 \mathrm{~h}$ at $37^{\circ} \mathrm{C}$ before treatment with $0,0.001,0.003,0.01$, $0.03,0.1,0.3,1$ or $3 \mu \mathrm{M}$ GCB for $24 \mathrm{hrs}$. The plated cell numbers were calculated to keep control T24 cells growing in the exponential phase throughout the incubation period. Cytotoxicity was evaluated using a serial dilution of each drug after $72 \mathrm{~h}$ treatment. Cells were treated with $100 \mu \mathrm{l} 0$, 12.5 or $25 \mathrm{mM}$ curcumin and 0,75 or $150 \mu \mathrm{M}$ resveratrol with or without GCB for $72 \mathrm{~h}$. Following which, $100 \mu \mathrm{l}$ MTT $(1 \mathrm{mg} / \mathrm{ml}$ in PBS) was added to each well and incubated for $3 \mathrm{~h}$ at $37^{\circ} \mathrm{C}$. The blue formazan crystals were dissolved in $100 \mu \mathrm{l}$ DMSO. The optical density was determined using absorbance spectrometry at $560 \mathrm{~nm}$ using a microplate reader (Multiskan ${ }^{\circledR}$ EX; Thermo Fisher Scientific, Inc.). A total of three separate experiments, run in triplicate were performed to obtain the mean cell viability. The drug concentrations inhibiting cell growth by $50 \%\left(\mathrm{IC}_{50}\right)$ were determined using Calcusyn software (v1.1; Biosoft).

$R N A$ preparation and reverse transcription-quantitative PCR (RT-qPCR) analysis of MDR-related mRNAs in T24 and T24-GCB cells. Total RNA was isolated from cells using TRIzol ${ }^{\circledR}$ reagent (Invitrogen; Thermo Fisher Scientific, Inc.) and treated with RQ1 RNase-free DNase (Promega Corporation) according to the manufacturer's instructions to remove genomic contamination. A total of $5 \mu \mathrm{g}$ treated RNA was used for RT with SuperScript III (Invitrogen; Thermo Fisher Scientific, Inc.) at $50^{\circ} \mathrm{C}$ for $1 \mathrm{~h}$. The thermocycling conditions for SYBR Green-based qPCR were: Initial denaturation at $95^{\circ} \mathrm{C}$ for $30 \mathrm{sec}$; followed by followed by 40 cycles of denaturation at $95^{\circ} \mathrm{C}$ for $5 \mathrm{sec}$, annealing at $60^{\circ} \mathrm{C}$ for $30 \mathrm{sec}$ and extension at $60^{\circ} \mathrm{C}$ for $30 \mathrm{sec}$; and a final extension step of $72^{\circ} \mathrm{C}$ for $20 \mathrm{sec}$. (Applied Biosystems; Thermo Fisher Scientific, Inc.) using 2X Hot Start PCR Master mix (Applied Biosystems; Thermo Fisher Scientific, Inc.), and GAPDH was used as an internal control and the $2^{-\Delta \Delta \mathrm{Cq}}$ method was used to quantify gene expression (12). Each treatment condition was run in six replicates. Primer sequences are provided in Table I.

Western blot analysis of MDR-related proteins in T24 and T24-GCB cells. Western blot analysis was used to identify changes in protein expression between T24-GCB and T24 UCC cells. Protein concentration was determined using a bicinchoninic acid assay. Several proteins were analyzed, including: ABCB1 (cat. no. 13342), ABCC2 (cat. no. 4446) and ABCG2 (cat. no. 4477; all Cell Signaling Technology, Inc.) for drug efflux, deoxycytidine kinase (DCK; cat. no. GTX632065), thymidine kinase (TK)1 (cat. no. GTX113281; both GeneTex, Inc) and TK2 (cat. no. ab123785; Abcam) for drug metabolism, and poly (ADP-ribose) polymerase (PARP; cat. no. 9542; Cell Signaling Technology, Inc.) cleavage for apoptosis. a-tubulin (cat. no. MS-581) was used as a loading control. Briefly, $1 \times 10^{6}$ treated cells were harvested using trypsin, washed with PBS twice and centrifuged at 3,000 x $\mathrm{g}$ for $5 \mathrm{~min}$ at room temperature. Cells were resuspended in $100 \mu \mathrm{l}$ RIPA buffer containing with cocktail protease inhibitor (Roche Diagnostics). A total of $50 \mu \mathrm{g}$ protein was separated using 10\% SDS-PAGE and transferred to PVDF membranes (EMD Millipore) using an electroblotter at $100 \mathrm{~V}$ for $1 \mathrm{~h}$ at $4^{\circ} \mathrm{C}$. The membranes were subsequently blocked with $5 \%$ skimmed milk for $1 \mathrm{~h}$ at room temperature. All primary antibodies were diluted 1:1,000 in TBS-Tween-20 (TBST) containing 5\% skimmed milk and membranes were incubated for $1 \mathrm{~h}$ at room temperature with 
Table I.Primer sequences for reverse transcription-quantitative PCR.

\begin{tabular}{|c|c|}
\hline Gene name & Primer sequence $\left(5^{\prime}-3^{\prime}\right)$ \\
\hline \multirow[t]{2}{*}{ ABCB1 } & F: GTTCTTCGATGAGCCCACCA \\
\hline & R: GCAGACTTTTCCCCGGTACA \\
\hline \multirow[t]{2}{*}{$\mathrm{ABCC} 1$} & F: TTCTCGGAAACCATCCACGA \\
\hline & R: AGTCTTGGCGCATTCCTTCT \\
\hline \multirow[t]{2}{*}{$\mathrm{ABCC} 2$} & F: TCCTGGTTCCTGTCCCTATTCT \\
\hline & R: AGGACGCTTGTAGCCTTTCA \\
\hline \multirow[t]{2}{*}{$\mathrm{ABCC} 3$} & F: CTTCCGCTTCACCACCTTCT \\
\hline & R: CCAGAGGTCCTTCTCCTCCA \\
\hline \multirow[t]{2}{*}{$\mathrm{ABCC} 4$} & F: GTGTACCAGGAGGTGAAGCC \\
\hline & R: GAGCGTGCAAAAAGTCAGCA \\
\hline \multirow[t]{2}{*}{ ABCC6 } & F: TGGGTCCTTGGTCCCATCTA \\
\hline & R: AGATTCCCTTCTACACCCCG \\
\hline \multirow[t]{2}{*}{$\mathrm{ABCC} 7$} & F: GAAAAAGGGTTGAGCGGCAG \\
\hline & R: GACCTCTGCATGGTCTCTCG \\
\hline \multirow[t]{2}{*}{$\mathrm{ABCC} 12$} & F: GCGTGTTGATGGACATCGTG \\
\hline & R: TAGTTGATGGCCCAGGCAAG \\
\hline \multirow[t]{2}{*}{ ABCD1 } & F: CTGGAACGCCTGTGGTATGT \\
\hline & R: CTCCACTGAGTCCGGGTAGA \\
\hline \multirow[t]{2}{*}{ ABCG1 } & F: GTTCTTCGATGAGCCCACCA \\
\hline & R: GCAGACTTTTCCCCGGTACA \\
\hline \multirow[t]{2}{*}{ ABCG2 } & F: CCACAGGTGGAGGCAAATCT \\
\hline & R: CAACCTTGGAGTCTGCCACT \\
\hline \multirow[t]{2}{*}{ GAPDH } & F: GTCTCCTCTGACTTCAACAGCG \\
\hline & R:ACCACCCTGTTGCTGTAGCCAA \\
\hline
\end{tabular}

ABC, ATP-binding cassette; F, forward; R, reverse.

gentle agitation. The blots were washed three times with TBST and incubated with goat anti-rabbit antibody or goat anti-mouse antibody conjugated to horseradish peroxidase (both from CST Biological Reagents Co., Ltd.; cat. nos. 7470 and 7076, respectively) for $1 \mathrm{~h}$ at room temperature. After three further washes with TBST, chemiluminescence reagent (Bio-Rad Laboratories, Inc.)was used for protein detection. The membrane was analyzed using a BioSpectrum 810 imaging system (UVP LLC) and densitometry analysis was performed Image J (V1.8.0_112).

Wound-healing assay. Tumor cell migratory ability was measured using a wound-healing assay. Briefly, $2 \times 10^{5}$ T24 and T24-GCB cells were seeded on a 12-well microplate for $8 \mathrm{~h}$ individually. When cells reached $90 \%$ confluence, wounds were created using a 1,000 $\mu \mathrm{l}$ tip, washed with PBS twice, and the culture medium was replaced with serum-starved medium containing either Curcumin $(10 \mu \mathrm{M})$ or resveratrol $(10 \mu \mathrm{M})$ at the start of the experiment $(0 \mathrm{~h})$. The diameter of the wound was imaged under light microscopy at x40 magnification (Olympus Corporation) at 6 and $12 \mathrm{~h}$. The diameter was measured from each picture using SPOT software version 5.6 (SPOT Imaging; Diagnostic Instruments, Inc.). Each experiment was repeated independently, at least three times.
Statistical analysis. Cytotoxicity, migrating cells, apoptotic changes, RNA and protein changes are presented as the mean \pm SD. Statistical analysis was performed in SPSS version 24.0 (IBM, Corp.). ANOVA with least significant difference post hoc test was used to analyze differences in the wound-healing assay, and the Student's t-test was used for all other statistical comparisons. $\mathrm{P}<0.05$ was considered to indicate a statistically significant difference.

\section{Results}

Cross-chemoresistance of T24-GCB cell line. The T24-GCB cell line was established successfully, and the drug sensitivity of GCB was confirmed using an MTT assay (Fig. 1). T24-GCB cells exhibited increased drug resistance, with an 18.75-fold higher ID $_{50}$ compared with that of native T24 cells (105.9 vs $5.6 \mathrm{nM}$; $\mathrm{P}<0.001$; Table II). In addition, Avastin, doxorubicin, epirubicin, mitomycin $\mathrm{C}$ and paclitaxel, which are comprehensively used chemotherapy drugs in clinical practice, were also selected to assess the drug resistance ability of T24 and T24-GCB cells. Cytotoxicity was evaluated using a serial dilution of each drug after $72 \mathrm{~h}$ treatment. Notably, T24-GCB cells were also cross-resistant to mitomycin $\mathrm{C}$ and paclitaxel $(\mathrm{P}<0.001)$. Although T24 cells appeared to be less resistant to epirubcin compared with their resistance to doxorubicin, there was no statistically significant difference in the sensitivities of either cell lines to both drugs (Fig. 1).

MDR-related mechanisms of T24-GCB cell line. Differences in the mRNA expression of drug efflux pumps between T24 and T24-GCB cells were compared using RT-qPCR, including ABCB1, ABCC1, ABCC2, ABCC3, ABCC4, ABCC6, $\mathrm{ABCC} 7, \mathrm{ABCC} 12, \mathrm{ABCD} 1, \mathrm{ABCG} 1$ and $\mathrm{ABCG} 2$. There were significantly higher mRNA expression levels of ABCC2 in T24-GCB cells compared with in T24 cells (Fig. 2A). With respect to the expression of membranous $\mathrm{ABC}$ proteins and cytoplasmic metabolism proteins in native T24 and MDR cell lines-T24-GCB, the protein expression of ABCC2 was significantly increased three-fold, and expression of ABCB1, ABCG2, DCK, TK1 and TK2 were significantly decreased in T24-GCB cells compared with the parental T24 cell line based on the densitometry analysis (Fig. 2B).

Chemoenhancement of $G C B$ by curcumin and resveratrol in the T24-GCB cell line. As shown in Fig. 3, curcumin and resveratrol demonstrated suppression of T24-GCB tumor cell growth independently and in a dose-dependent manner. When combined with GCB, there was an additive effect of curcumin and resveratrol on cytotoxicity. In Fig. 3, the $\mathrm{O} / \mathrm{E}$ ratio was used to assess the effects of combinations of compounds and the result was statistically significant (Fig. 3C and D) There was a significant difference observed in GCB-treated $(\mathrm{P}<0.001)$ or $\mathrm{GCB}$ plus resveratrol-treated $(\mathrm{P}<0.01$ and $\mathrm{P}<0.001)$ T24-GCB cells compared with the control (Fig. 3B).

Migratory ability modulation by curcumin in T24 and T24-GCB cell lines. A wound-healing assay was used to determine the migratory abilities of T24 and T24-GCB cells; T24-GCB showed a similar migratory ability to T24 in the 
Table II. IC of GCB in T24 and T24-GCB cells, measured using an MTT assay.

\begin{tabular}{lccc}
\hline Cell type & $\mathrm{IC}_{25}, \mathrm{nM}($ mean $\pm \mathrm{SD})$ & $\mathrm{IC}_{50}, \mathrm{nM}($ mean $\pm \mathrm{SD})$ & $\mathrm{IC}_{75}, \mathrm{nM}(\mathrm{mean} \pm \mathrm{SD})$ \\
\hline T24 & $2.9 \pm 0.8$ & $5.6 \pm 1.4$ & $10.8 \pm 2.6$ \\
T24-GCB & $56.4 \pm 23.9$ & $105.9 \pm 42.7$ & $198.7 \pm 76.0$ \\
\hline
\end{tabular}

GCB, gemcitabine; IC, inhibitory concentration.
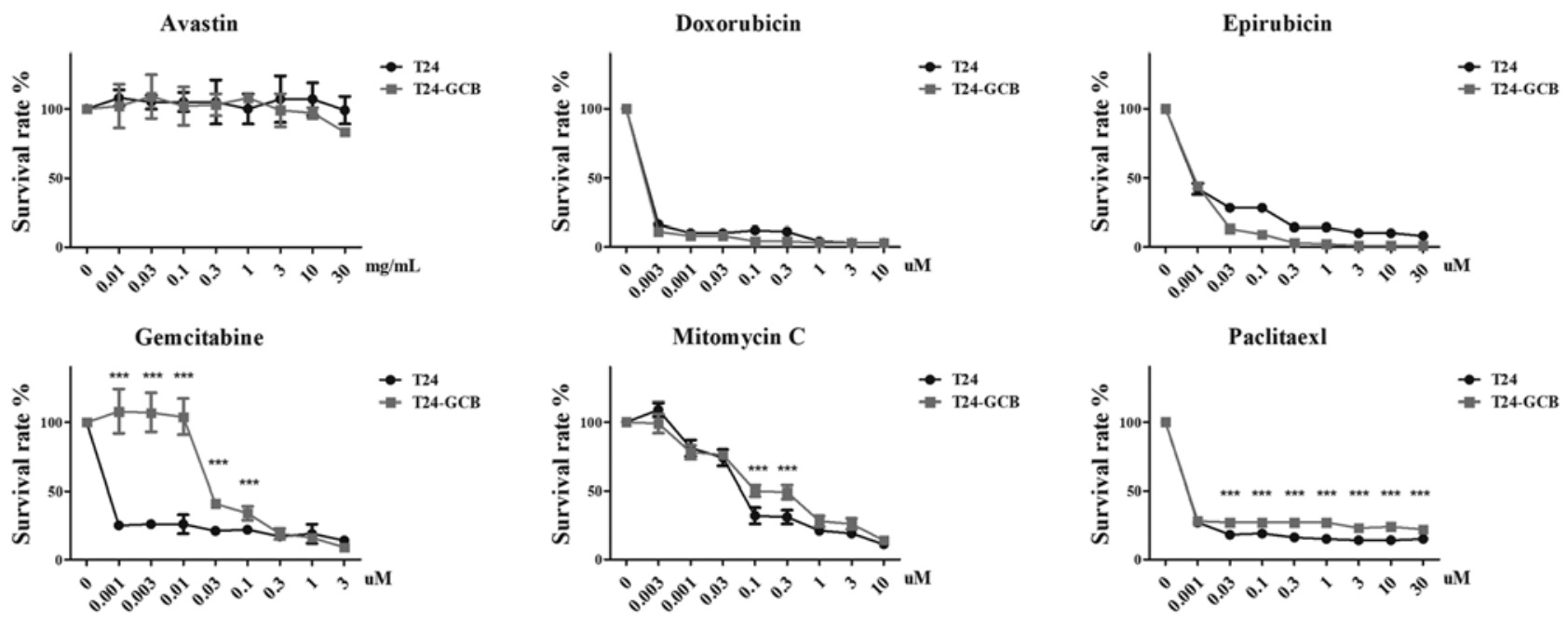

Figure 1. Chemoresistance of T24-GCB cells. MTT assay to determine the cytotoxicity of Avastin, doxorubicin, epirubicin, gemcitabine, mitomycin C and paclitaxel in T24 and T24-GCB cells. ${ }^{* * *} \mathrm{P}<0.001$. GCB, gemcitabine.

A

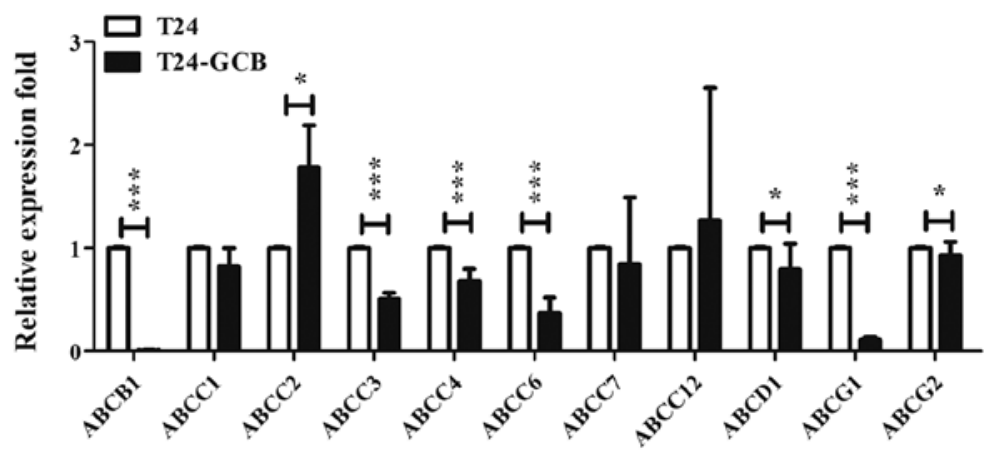

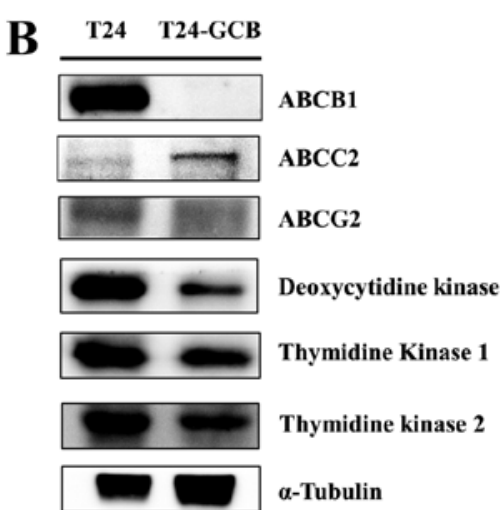

B

Figure 2. Molecular variation of ABC transporters and GCB-activating enzymes in T24-GCB cells. (A) mRNA expression of ABC transporters in T24 and T24-GCB cells, as determined via reverse transcription-quantitative PCR analysis. GAPDH was used as an internal reference, and T24 cells were used as the control group. (B) Western blot analysis of ABCB1, ABCC2, ABCG2, deoxycytidine kinase, TK1 and TK2 protein expression in T24 and T24-GCB cells. ${ }^{*} \mathrm{P}<0.05,{ }^{* * *} \mathrm{P}<0.001$. ABC, ATP-binding cassette; TK, thymidine kinase; GCB, gemcitabine.

control group after a $6 \mathrm{~h}$ treatment. After a $12 \mathrm{~h}$ treatment with curcumin and resveratrol (both $10 \mu \mathrm{M}$ ), curcumin significantly reduced T24-GCB migration compared with that of T24-GCB control cells $(\mathrm{P}<0.001)$, and resveratrol slightly but significantly decreased the migratory ability of T24-GCB cells $(\mathrm{P}<0.05$; Fig. 4). There was a significant difference in the migratory ability of the T24 control group compared with that of the T24-GCB group $(\mathrm{P}<0.05)$. Curcumin and resveratrol treatment demonstrated significant inhibition of migration in T24-GCB cells.
Mechanism of MDR modulation by curcumin and resveratrol in the T24-GCB cell line. As aforementioned, it was proposed that drug resistance in T24-GCB cells results from upregulation of $\mathrm{ABCC} 2$, and downregulation of DCK, TK1 and TK2. Subsequently, these proteins were evaluated in T24-GCB cells treated with curcumin $(25 \mu \mathrm{M})$ or resveratrol $(150 \mu \mathrm{M})$, alone or in combination with GCB. As shown in Fig. 5, curcumin and resveratrol resulted in an increase in ABCC2 expression and a decrease in DCK, TK1 and TK2 expression compared with T24-GCB control. 
A

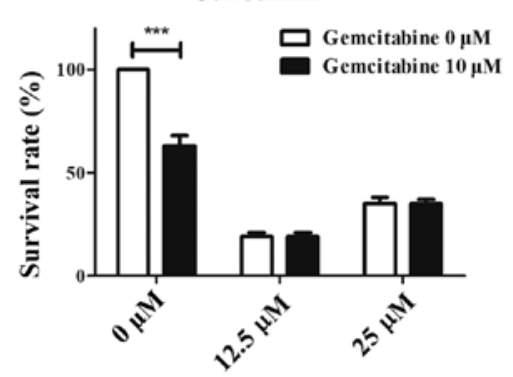

C

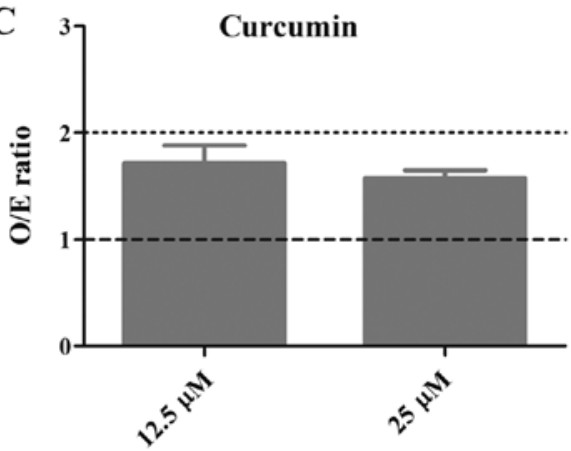

B

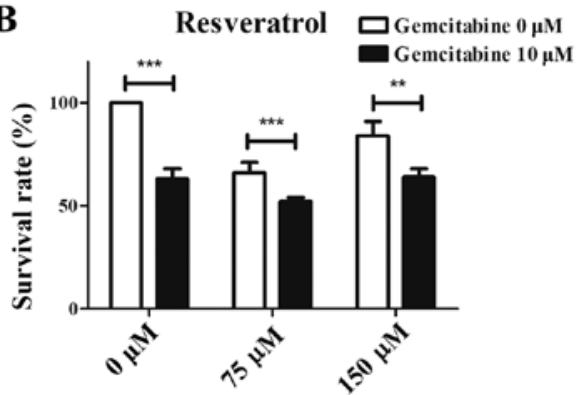

D

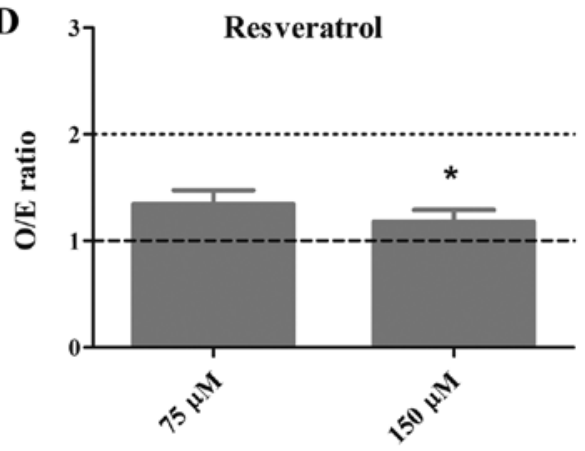

Figure 3. Cytotoxic effects of combined treatment. (A) The cytotoxicity of curcumin alone or combined with GCB in T24-GCB cells. (B) The cytotoxicity of resveratrol alone or combined with GCB in T24-GCB cells. (C) The O/E ratio compared between GCB combined with low-dose (12.5 $\mu \mathrm{M})$ or high-dose $(25 \mu \mathrm{M})$ curcumin in T24-GCB cells. (D) The O/E ratio compared between GCB combined with low-dose (75 $\mu \mathrm{M})$ or high-dose (150 $\mu \mathrm{M})$ resveratrol in T24-GCB cells. Significant difference was observed between GCB-treated T24-GCB cells combined with low-dose and high-dose of resveratrol. "P<0.05, ${ }^{* *} \mathrm{P}<0.01,{ }^{* * *} \mathrm{P}<0.001$. GCB, gemcitabine; $\mathrm{O} / \mathrm{E}$, the ratio of observed deaths/expected deaths.

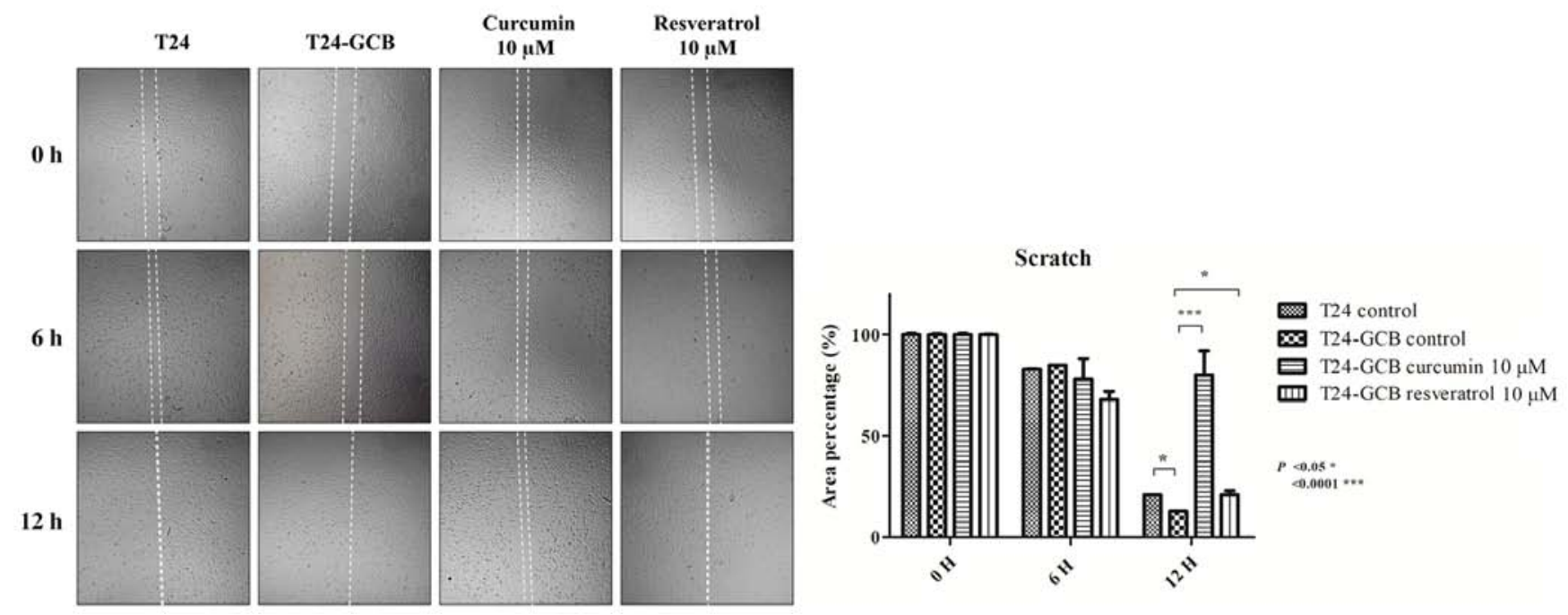

Figure 4. Effect of the combined treatment on migration. Wound-healing assay for T24 control group, T24-GCB control group, and T24-GCB cells treated with either curcumin or resveratrol. Significant differences were observed between T24 controls compared with T24-GCB controls, and T24-GCB controls compared with curcumin-treated and resveratrol-treated T24-GCB cells. ${ }^{*} \mathrm{P}<0.05,{ }^{* * *} \mathrm{P}<0.001$. GCB, gemcitabine.

Curcumin or resveratrol treatment alone had similar effects, and the combination treatments exerted a more pronounced affect.

Apoptotic changes in the T24-GCB cell line. The protein expression of PARP, which is associated with apoptotic activity, was increased in T24-GCB control cells compared with that in T24-GCB cells treated with $25 \mu \mathrm{M}$ curcumin or $150 \mu \mathrm{M}$ resveratrol for $24 \mathrm{hrs}$ (Fig. 6).

\section{Discussion}

In the present study, the GCB-resistant cancer cells were found be resistant to mitomycin $\mathrm{C}$ and paclitaxel which is consistent with a previous study (13) With respect to the mechanism of MDR, in previous studies, expression of human equilibrative nucleoside transporter 1 and DCK protein expression levels were decreased, whereas ribonucleotide reductase catalytic subunit M1 protein was increased in association with the 

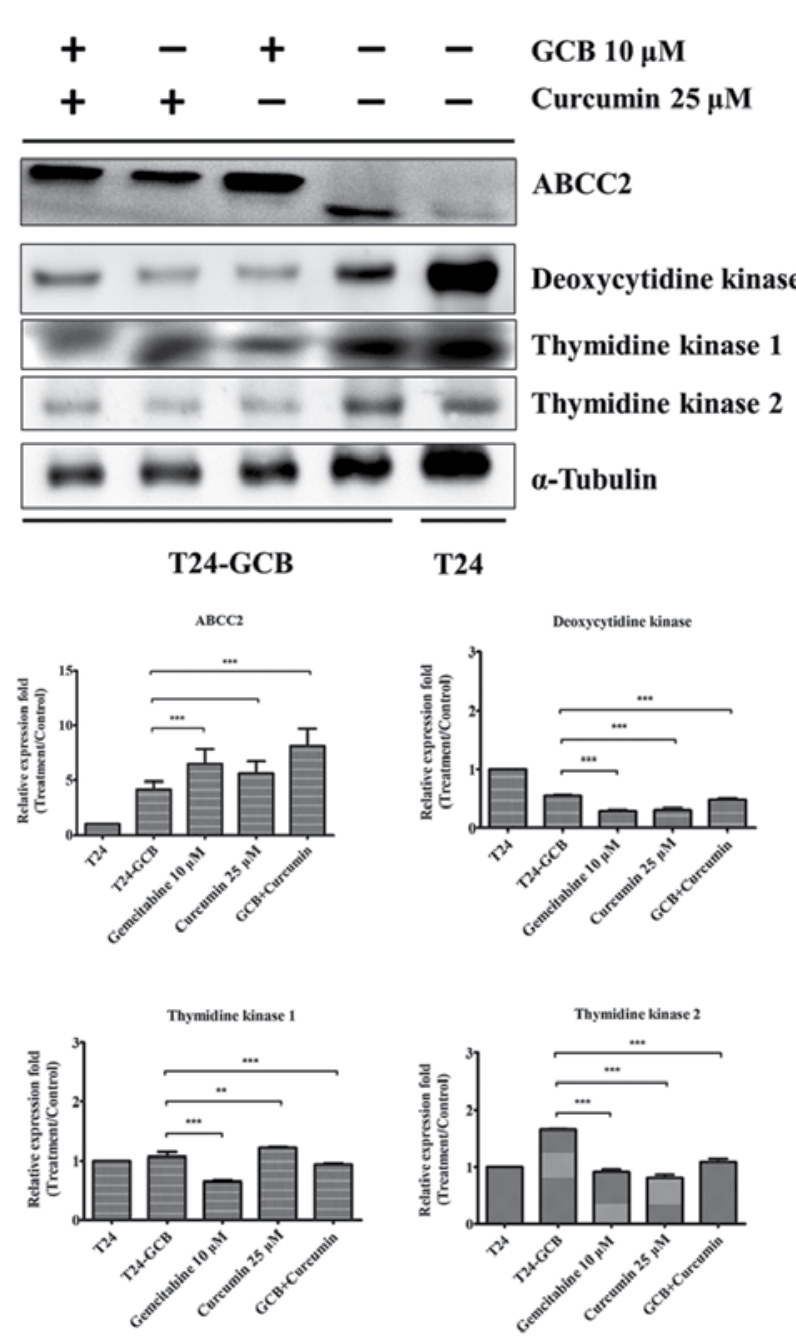
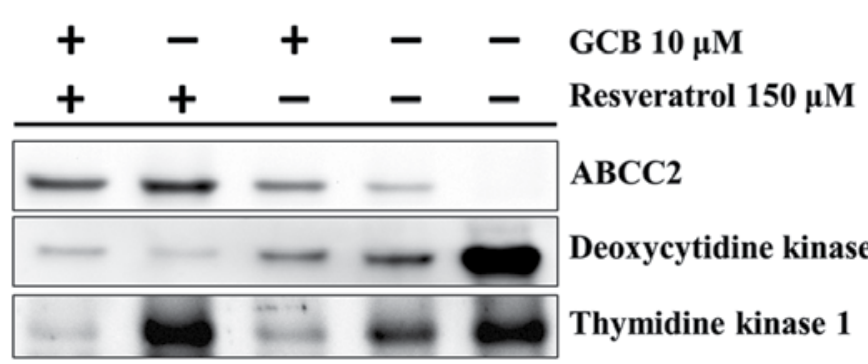

ABCC2

Deoxycytidine kinase

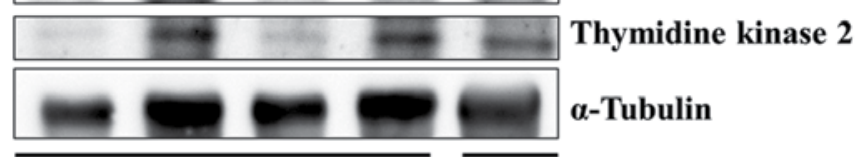

T24-GCB

T24
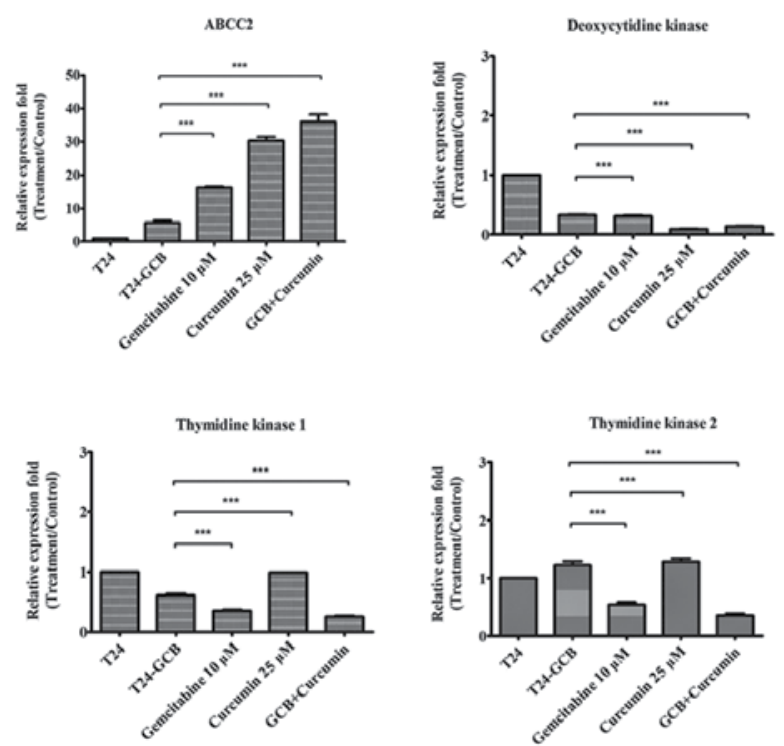

Figure 5. Molecular regulatory effects of combined treatment. Western blot analysis of ABCC2, deoxycytidine kinase, TK1 and TK2 proteins in T24 control group, T24-GCB control group, T24-GCB cells treated with GCB, and T24-GCB cells treated with curcumin or resveratrol, alone or in combination with GCB. ${ }^{* *} \mathrm{P}<0.01$ and ${ }^{* * *} \mathrm{P}<0.001$. ABCC2, ATP-binding cassette subfamily $\mathrm{C}$ member 2 ; TK, thymidine kinase, GCB, gemcitabine.
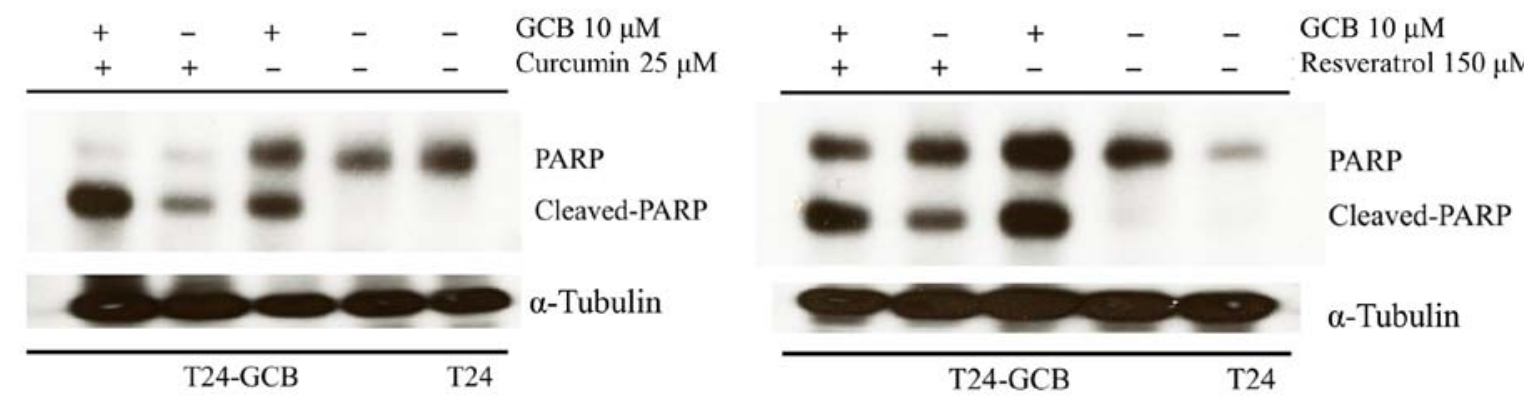

Figure 6. Apoptotic effects of combined treatment. Western blot analysis of PARP in T24 control group, T24-GCB control group, T24-GCB cells treated with gemcitabine $10 \mu \mathrm{M}$, and T24-GCB cells treated with either curcumin $25 \mu \mathrm{M}$ or resveratrol $150 \mu \mathrm{M}$, alone or in combination with GCB. PARP, poly (ADP-ribose) polymerase, GCB, gemcitabine.

acquisition of GCB resistance in non-small cell lung cancer cells $(14,15)$. In the present study, DCK protein expression levels were decreased, and TK1 and TK2 protein levels were also decreased in GCB-resistant UCC cells. Conversely, the importance of $\mathrm{ABC}$ transporters in mediating drug efflux is well documented and associated with $\mathrm{GCB}$ resistance in tumor cells. ABCB1, ABCC1 and ABCG2 expression levels are increased in leukemia and lung cancer cells. (16,17). In the present study, ABCC2 expression was markedly increased in GCB-resistant UCC cells. This indicated that GCB-resistant UCC cells established their drug resistance primarily through membranous ABCC2 overexpression $(18,19)$. The upregulation of $\mathrm{ABCC} 2$ and downregulation of other $\mathrm{ABC}$ transporter members compared in the present study suggests that long-term 
GCB treatment-induced MDR may be associated with efflux of drugs through the membrane via ABCC2.

Curcumin is reported to induce cell cycle arrest and apoptosis in vitro in several different types of cancer by modulating multiple signaling pathways, including NF- $\mathrm{B}$, cyclooxygenase-2, tumor necrosis factor- $\alpha$, STAT-3 and cyclin D1, reviewed in (20). Curcumin can induce the apoptosis of human osteosarcoma cells through caspase- 3 activation and PARP cleavage (21). In addition to effects on the cell cycle and apoptosis, curcumin also exhibits anticancer properties by regulating cell survival, proliferation, angiogenesis, invasion and metastasis (22). It can also inhibit the migration and autophagy-dependent Akt degradation in MDA-MB-231 cells (22). Curcumin can also reverse MDR by decreasing the expression and function of $\mathrm{ABCB} 1$ and by promoting the activation of caspase-3 in gastric cancer cells $(23,24)$. Patel and Majumdar (25) reported that curcumin combined with current chemotherapeutics such as 5-fluorouracil, oxaliplatin and GCB enhanced the chemotherapeutic effects in gastrointestinal cancer. In the present study, it was observed that curcumin increased the expression of $\mathrm{ABCC} 2$ and cleaved PARP, but decreased the expression of DCK, TK1 and TK2, and inhibited migration of T24-GCB cells. Therefore curcumin not only modulated the growth and MDR of GCB-resistant UCC cells through inhibition of GCB activating or sensitizing enzymes, but also enhanced apoptosis by increasing PARP cleavage.

Resveratrol induces its anticancer effects in different types of tumors, such as colon-rectal cancer, neuroendocrine tumor, liver cancer and prostate cancer, by participating in multiple signaling pathways to induce apoptosis in cancer cells reviewed in references $(26,27)$. Resveratrol has been reported to inhibit cancer cell proliferation, induce cell cycle arrest and apoptosis, and these anticancer effects may be due to its ability to modulate signaling molecules involved in these processes, such as inhibition of AKT, RAS/ERK and JAK/STAT3 signaling pathways (28).

Resveratrol blocks cell cycle via modulation of key regulators, and promotes apoptosis via p53-dependent and -independent mechanisms in prostate cancer (29). Resveratrol induced antiproliferation/apoptosis in various types of cancers, such as prostate, breast, colon, gastric and melanoma (29-31), and was also found to be involved in the inhibition of ABC transporters, and regulation of several pathways such as PTEN/AKT (32). The present findings suggested that resveratrol combined with GCB caused an increase in cleaved PARP and ABCC2 expression and a decrease in DCK, TK1 and TK2 expression.

In conclusion, both curcumin and resveratrol resensitized the drug resistance of T24-GCB cells to GCB combined therapy, potentially through affecting ABCC2, DCK, TK1 and TK2 function and thereby increasing PARP cleavage and apoptosis.

\section{Acknowledgements}

Not applicable.

\section{Funding}

The present study was supported by grants from the Ministry of Science and Technology Taiwan (grant nos. MOST 106-2320-B-016-013-MY3 and MOST-104-2314-B-016-040-MY3), Tri-Service General Hospital (Taipei, Taiwan R.O.C.; grant nos. TSGH-C107-062 and TSGH-C106-045), National Defense Medical Center (grant no. MAB-107-089; Taipei, Taiwan R.O.C.) and Cheng Hsin General Hospital (Taipei, Taiwan R.O.C. grant nos. CH-NDMC-105-7 and CH-NDMC-106-06).

\section{Availability of data and materials}

The datasets used and/or analyzed during the present study are available from the corresponding author on reasonable request.

\section{Authors' contributions}

DSY, CPY, STW and CWY conceived and designed the study. CJC performed the experiments. DSY, CLW, JYH and CJC analyzed the data. DSY and CJC wrote the paper. DSY revised the manuscript. All authors read and approved the final manuscript for publication.

\section{Ethics approval and consent to participate}

Not applicable.

\section{Patient consent for publication}

Not applicable.

\section{Competing interests}

The authors declare that they have no competing interests.

\section{References}

1. Luqmani YA: Mechanisms of drug resistance in cancer chemotherapy. Med Princ Pract 14 (Suppl 1): S35-S48, 2005.

2. Nguyen DP and Thalmann GN: Contemporary update on neoadjuvant therapy for bladder cancer. Nat Rev Urol 14: 348-358, 2017.

3. Chai S, To KK and Lin G: Circumvention of multi-drug resistance of cancer cells by Chinese herbal medicines. Chin Med 5: 26, 2010.

4. Vasiliou V, Vasiliou K and Nebert DW: Human ATP-binding cassette (ABC) transporter family. Hum Genomics 3: 281-290, 2009.

5. Chen Z, Shi T, Zhang L, Zhu P, Deng M, Huang C, Hu T, Jiang L and Li J: Mammalian drug efflux transporters of the ATP binding cassette $(\mathrm{ABC})$ family in multidrug resistance: A review of the past decade. Cancer Lett 370: 153-164, 2016.

6. Fedier A, Dedes KJ, Imesch P, Von Bueren AO and Fink D. The histone deacetylase inhibitors suberoylanilide hydroxamic (vorinostat) and valproic acid induce irreversible and MDR1-independent resistance in human colon cancer cells. Int J Oncol 31: 633-641, 2007.

7. Collett GP, Robson CN, Mathers JC and Campbell FC: Curcumin modifies Apc(min) apoptosis resistance and inhibits 2-amino 1-methyl-6-phenylimidazo[4,5-b]pyridine (PhIP) induced tumour formation in Apc(min) mice. Carcinogenesis 22: 821-825, 2001.

8. Chen KG and Sikic BI: Molecular pathways: Regulation and therapeutic implications of multidrug resistance. Clin Cancer Res 18: 1863-1869, 2012.

9. Sapienza C and Issa JP: Diet, nutrition, and cancer epigenetics. Annu Rev Nutr 36: 665-681, 2016.

10. Collins AR, Azqueta A and Langie SA: Effects of micronutrients on DNA repair. Eur J Nutr 51: 261-279, 2012.

11. Royston KJ and Tollefsbol TO: The epigenetic impact of cruciferous vegetables on cancer prevention. Curr Pharmacol Rep 1: 46-51, 2015.

12. Livak KJ and Schmittgen TD: Analysis of relative gene expression data using real-time quantitative PCR and the 2(-Delta Delta C(T)) method. Methods 25: 402-408, 2001. 
13. Wattanawongdon W, Hahnvajanawong C, Namwat $\mathrm{N}$, Kanchanawat S, Boonmars T, Jearanaikoon P, Leelayuwat C, Techasen A and Seubwai W: Establishment and characterization of gemcitabine-resistant human cholangiocarcinoma cell lines with multidrug resistance and enhanced invasiveness. Int J Oncol 47: 398-410, 2015.

14. Achiwa H, Oguri T, Sato S, Maeda H, Niimi T and Ueda R: Determinants of sensitivity and resistance to gemcitabine: The roles of human equilibrative nucleoside transporter 1 and deoxycytidine kinase in non-small cell lung cancer. Cancer Sci 95 753-757, 2004

15. Davidson JD, Ma L, Flagella M, Geeganage S, Gelbert LM and Slapak CA: An increase in the expression of ribonucleotide reductase large subunit 1 is associated with gemcitabine resistance in non-small cell lung cancer cell lines. Cancer Res 64: 3761-3766, 2004.

16. Modok S, Mellor HR and Callaghan R: Modulation of multidrug resistance efflux pump activity to overcome chemoresistance in cancer. Curr Opin Pharmacol 6: 350-354, 2006.

17. Zaman GJ, Flens MJ, van Leusden MR, de Haas M, Mülder HS Lankelma J, Pinedo HM, Scheper RJ, Baas F, Broxterman HJ, et al: The human multidrug resistance-associated protein MRP is a plasma membrane drug-efflux pump. Proc Natl Acad Sci USA 91: 8822-8826, 1994.

18. Sodani K, Patel A, Kathawala RJ and Chen ZS: Multidrug resistance associated proteins in multidrug resistance. Chin J Cancer 31: 58-72, 2012.

19. Chen ZS and Tiwari AK: Multidrug resistance proteins (MRPs/ABCCs) in cancer chemotherapy and genetic diseases. FEBS J 278: 3226-3245, 2011.

20. Shehzad A, Wahid F and Lee YS: Curcumin in cancer chemoprevention: Molecular targets, pharmacokinetics, bioavailability, and clinical trials. Arch Pharm (Weinheim) 343: 489-499, 2010

21. Lee DS, Lee MK and Kim JH: Curcumin induces cell cycle arrest and apoptosis in human osteosarcoma (HOS) cells. Anticancer Res 29: 5039-5044, 2009.

22. Guan F, Ding Y, Zhang Y, Zhou Y, Li M and Wang C: Curcumin suppresses proliferation and migration of MDA-MB-231 breast cancer cells through autophagy-dependent Akt degradation. PLoS One 11: e0146553, 2016.
23. Limtrakul P, Anuchapreeda S and Buddhasukh D: Modulation of human multidrug-resistance MDR-1 gene by natural curcuminoids. BMC Cancer 4: 13, 2004.

24. Tang XQ, Bi H, Feng JQ and Cao JG: Effect of curcumin on multidrug resistance in resistant human gastric carcinoma cell line SGC7901/VCR. Acta Pharmacol Sin 26: 1009-1016, 2005.

25. Patel BB and Majumdar AP: Synergistic role of curcumin with current therapeutics in colorectal cancer: Minireview. Nutr Cancer 61: 842-846, 2009.

26. Mukhtar E, Adhami VM, Khan N and Mukhtar H: Apoptosis and autophagy induction as mechanism of cancer prevention by naturally occurring dietary agents. Curr Drug Targets 13: 1831-1841, 2012.

27. Varoni EM, Lo Faro AF, Sharifi-Rad J and Iriti M: Anticancer molecular mechanisms of resveratrol. Front Nutr 3: 8, 2016.

28. Yousef M, Vlachogiannis IA and Tsiani E: Effects of resveratrol against lung cancer: In vitro and in vivo studies. Nutrients 9: E1231, 2017.

29. Lin HY, Shih A, Davis FB, Tang HY, Martino LJ, Bennett JA and Davis PJ: Resveratrol induced serine phosphorylation of p53 causes apoptosis in a mutant p53 prostate cancer cell line. J Urol 168: 748-755, 2002.

30. Holian O, Wahid S, Atten MJ and Attar BM: Inhibition of gastric cancer cell proliferation by resveratrol: Role of nitric oxide. Am J Physiol Gastrointest Liver Physiol 282: G809-G816, 2002.

31. Manna SK, Mukhopadhyay A and Aggarwal BB: Resveratrol suppresses TNF-induced activation of nuclear transcription factors NF-kappa B, activator protein-1, and apoptosis: Potential role of reactive oxygen intermediates and lipid peroxidation. J Immunol 164: 6509-6519, 2000.

32. Wang Y, Romigh T, He X, Orloff MS, Silverman RH, Heston WD and Eng C: Resveratrol regulates the PTEN/AKT pathway through androgen receptor-dependent and -independent mechanisms in prostate cancer cell lines. Hum Mol Genet 19: 4319-4329, 2010 